\title{
REDOX CYCLING OF FE- BEARING CLAY MINERALS using aqueous Fe(II): impacts on mineral STRUCTURE, identity AND REACTIVITY
}

HARRY BROOKSBANK AND ANKE NEUMANN

Newcastle University

Presenting Author: h.brooksbank2@newcastle.ac.uk

Iron is abundant in natural sediments, and the $\mathrm{Fe}(\mathrm{II})-\mathrm{Fe}(\mathrm{III})$ redox couple plays a vital role in the cycling of nutrients and the fate of various environmental contaminants. Clay minerals contain octahedral $\mathrm{Fe}$ in their mineral structure, which is thought to be resistant to reductive dissolution and which, after reduction, can reductively degrade a variety of organic compounds. Although sediments and soils are likely to experience natural fluctuations in redox chemistry over time, most research has focussed on exploring clay mineral redox reactivity upon initial Fe reduction, without regard for how multiple cycles of reduction and oxidation might impact the long-term efficacy of Fe-bearing clay minerals. Interestingly, clay mineral $\mathrm{Fe}$ can be reduced abiotically by electron transfer from microbially produced aqueous $\mathrm{Fe}(\mathrm{II})$, which becomes oxidised and forms potentially reactive $\mathrm{Fe}$ precipitate(s) in the process. This project aims to understand how multiple cycles of reduction with aqueous Fe(II) and subsequent oxidation impact clay mineral structure and reactivity towards contaminants, including investigating the identity and role of minerals precipitated during the process.

We subjected a high Fe content clay mineral (NAu-1) to three subsequent cycles of reduction and oxidation, using $3.5 \mathrm{mM}$ aqueous $\mathrm{Fe}(\mathrm{II})$ as the reducing agent, and hydrogen peroxide as oxidant. We assessed mineral reactivity by monitoring the reductive degradation of our reactive probe compound 3chloronitrobenzene (3ClNB). Analysis of 3CINB degradation kinetics shows a significant increase of reaction rate constants in the second redox cycle, suggesting that the secondary precipitates formed may contribute to the overall reactivity in the system. Using Mössbauer spectroscopy in conjunction with aqueous $\mathrm{Fe}(\mathrm{II})$ enriched in Mössbauer-visible / -invisible Fe isotopes, we examined the extent of electron transfer to clay mineral $\mathrm{Fe}$ and characterised the formed precipitates. Complementary solid phase analysis with XRD confirms that reoxidised samples contained mainly lepidocrocite with increasing amounts of goethite in later cycles. Ongoing work focusses on completing the comprehensive characterisation of secondary Fe precipitates, to understand how clay minerals and precipitates interact, change across repeated redox cycles and affect the observed reactivity towards contaminant degradation. 